Check for updates

Cite this: RSC Adv., 2018, 8, 34848

\title{
The hydrothermal processing of iron oxides from bacterial biofilm waste as new nanomaterials for broad applications $\uparrow$
}

\author{
Le $\mathrm{Yu}^{a}{ }^{\mathrm{a}}$ Diana N. H. Tran, (D) ${ }^{\text {ab }}$ Peter Forward, ${ }^{\mathrm{c}}$ Martin F. Lambert ${ }^{\mathrm{d}}$ \\ and Dusan Losic (iD *ab
}

Iron oxides and their hydroxides have been studied and analysed with properties of their mutual transformations under different hydrothermal conditions being indicated. Amorphous bacteria nanowires produced from biofilm waste were investigated under the influence of $\mathrm{pH}$ at a fixed duration $(20 \mathrm{~h})$ and reaction temperature $\left(200^{\circ} \mathrm{C}\right)$. The morphology, structure, and particle size of the transformation of hematite $\left(\alpha-\mathrm{Fe}_{2} \mathrm{O}_{3}\right)$ was obtained and characterised with SEM, XRD, FTIR, and particle sizer. The optimal conditions for the complete conversion of amorphous iron oxide nanowires to crystalline $\alpha-\mathrm{Fe}_{2} \mathrm{O}_{3}$ is under acidic conditions where the $\mathrm{pH}$ is 1 . The flower-like $\alpha-\mathrm{Fe}_{2} \mathrm{O}_{3}$ structures have photocatalytic activity and adsorbent properties for heavy metal ions. This one-pot synthesis approach to produce $\alpha-\mathrm{Fe}_{2} \mathrm{O}_{3}$ at a low cost would be greatly applicable to the recycling process of biofilm waste in order to benefit the environment.

Received 23rd August 2018

Accepted 5th October 2018

DOI: $10.1039 / c 8 \mathrm{ra07061j}$

rsc.li/rsc-advances

adsorbent for the removal of arsenic in wastewater. ${ }^{5}$ Their

\section{Introduction}

Nanomaterials have drawn a great deal of attention from both the public and scientific community due to their characteristic properties, which are dependent on their morphology, particle size and assembly patterns. ${ }^{1}$ Many works have tried to establish effective and feasible synthesis methods in order to control their assembly behaviours and morphology to further tailor their properties. ${ }^{2}$ One-dimensional (1D) nanostructures, such as nanowires, are interesting materials that can be naturally sourced from bacteria biofilms (Bac-FeOxs) which are abundant in South Australia (Australia). This versatile produced biofilm waste is found in the groundwater pumping system pipelines of the Murray River that require periodic cleaning to stop clogging from the accumulation of salt and bacteria (Mariprofundus ferrooxydans). This biofilm waste is comprised of ferromagnetic iron oxide wires with many unique properties. Our recent works have shown that they can be used as an efficient magnetic photocatalyst due to their structural performance under visible light irradiation, which could be applicable for cancer therapy ${ }^{3,4}$ and also be used as an

${ }^{a}$ School of Chemical Engineering, The University of Adelaide, Adelaide, SA 5005, Australia.E-mail:dusan.losic@adelaide.edu.au

${ }^{b} A R C$ Graphene Enabled Industry Transformation Hub, The University of Adelaide, Adelaide, SA 5005, Australia

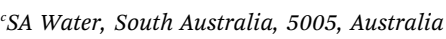

${ }^{d}$ School of Civil, Environmental and Mining Engineering, The University of Adelaide, Adelaide, SA 5005, Australia. E-mail: martin.lambert@adelaide.edu.au

$\dagger$ Electronic supplementary information (ESI) available. See DOI: $10.1039 / \mathrm{c} 8 \mathrm{ra0} 07061 \mathrm{j}$ wide usage in paints, coatings, cosmetics, magnetic and construction materials is also due to their chemical stability, low cost, high durability and high strength. ${ }^{6}$ A different study has shown that by catalysing hydrogen peroxide for the generation of free-radicals the biofilm can degrade, and also hinder its accumulation on human teeth. ${ }^{7,8}$ Some of the common methods to synthesize iron oxides are surfactant mediated-precipitation, chemical precipitation, electrodeposition and micro-wave assisted hydrothermal techniques. However, these methods are limited as the particle size and morphology cannot be tailored and applied to certain functions. ${ }^{9}$ Hydrothermal reduction is a simple method that can easily be implemented in industry as it requires only a 'one-pot' reaction. The transformation from an amorphous to a crystalline structure under thermal annealing has been demonstrated to give the nanowire a unique crystal-phase configuration without changing its morphology. ${ }^{2}$ Therefore, the recycling of this biofilm waste not only would decrease pollution and environmental waste but would also be a useful regenerative source for potential applications which is beneficial for the environment, economy and society.

Iron oxide (such as magnetite, $\mathrm{Fe}_{3} \mathrm{O}_{4}$ ) pigments have numerous desirable attributes as colouring agents, especially in cosmetics, as they can range in colours with high tinting strength. In addition, they are extremely stable (no fading and no bleeding) and are highly resistant. There are two major methods used to produce these iron oxides. One is to oxidize the iron metal with water and the other is to reduce hematite $\left(\mathrm{Fe}_{2} \mathrm{O}_{3}\right)$ with hydrogen $\left(\mathrm{H}_{2}\right)$ as shown in eqn (1) and (2), respectively: ${ }^{10}$ 


$$
\begin{gathered}
\mathrm{Fe}+4 \mathrm{Fe}_{2} \mathrm{O}_{3}=3 \mathrm{Fe}_{3} \mathrm{O}_{4} \\
3 \mathrm{Fe}_{2} \mathrm{O}_{3}+\mathrm{H}_{2}=2 \mathrm{Fe}_{3} \mathrm{O}_{4}+\mathrm{H}_{2} \mathrm{O}
\end{gathered}
$$

The reduction of $\mathrm{Fe}_{2} \mathrm{O}_{3}$ to $\mathrm{Fe}_{3} \mathrm{O}_{4}$ needs to be synthesized at both elevated pressure and temperature when it is in the presence of water. Both reactions need to be performed under hydrothermal conditions.

Iron oxides and their hydroxides have been studied and analysed with indicating properties of their mutual transformations under different hydrothermal conditions. Most of their transformations are set examples of a phenomenon called topotaxy. ${ }^{11}$ This phenomenon signifies the change of one solid crystalline phase to another form. It is believed that both two phases share a fixed structural relationship with one another. Within the iron oxide system, most transformations are well known, which have been examined and analysed in rational crystallochemical methods. ${ }^{12}$ The major six crystal structures of oxides and hydroxides iron are hematite, magnetite, maghemite, wustite, goethite and lepidocrocite. They are composed of various stackings of oxygen or hydroxyl sheets combined with different arrangement of iron ions in tetrahedral or octahedral spaces. ${ }^{\mathbf{1 1}}$ Therefore, this structure could impact on the properties of one another within the iron oxide system. When the sheets are stacked differently, the structure will transform and automatically rearrange with a distinct stacking formation, where each sheet will share a strong link associated with each other. For the formation of a particular iron oxide, the annealing temperature and $\mathrm{pH}$ during the hydrothermal process is critical as this will affect the crystal structure of the material. Table 1 summarizes the different formation requirements of each oxide and hydroxide of iron under hydrothermal conditions. However, it is unclear where the optimised conditions are for the different iron oxide formation due to the very few and inconclusive available data in the current literature whether it is the time, temperature, or $\mathrm{pH}$.

To our knowledge there is no study on the hydrothermal reduction of iron oxides from Bac-FeOxs, which we present here. The aim of this work is to demonstrate for the first time the hydrothermal processing of iron oxides from biofilm waste in a 'one-pot' synthesis reaction. The conversion of hematite was targeted as it is the most important ore of iron. The temperature and $\mathrm{pH}$ of the hydrothermal process were optimised and the changes in structure were analysed. The synthesis method is simple and free of toxic wastes which can be scaled for industry.

\section{Experimental}

\section{Materials and chemicals}

Bacterial biofilms (Bac-FeOxs) were provided by SA Water (South Australia, Australia). Hydrochloric acid ( $\mathrm{HCl}, 35 \%)$ and ammonium solution $\left(\mathrm{NH}_{4} \mathrm{OH}, 30 \%\right)$ were purchased from ChemSupply (Australia). All chemicals were used directly without further processing. Distilled (DI) water was used throughout the study, unless otherwise stated.

\section{Purification and hydrothermal reduction of Bac-FeOxs}

Bac-FeOxs were purified by washing the samples multiple times with DI water with a centrifuge (Sigma 3-18, John Morris, Australia) at $4200 \mathrm{rpm}$ for $20 \mathrm{~min}$ until the conductivity (Thermo Scientific, Orion Star A212, Australia) of the samples reached that of DI water. This indicated that the salt impurities were successfully removed from the samples. X-ray diffraction (XRD, Rigaku MiniFlex 600, Japan) was also used to confirm the purity of the samples when no salt (i.e. sodium chloride, $\mathrm{NaCl}$ ) peaks were measured. The samples were then dried at $60{ }^{\circ} \mathrm{C}$ in an oven overnight. For the hydrothermal process, $2.5 \mathrm{~g}$ of the purified Bac-FeOxs (P-Bac-FeOxs) were homogeneously mixed in $40 \mathrm{ml}$ DI water for $30 \mathrm{~min}$ and the $\mathrm{pH}$ of the solution was adjusted from to 1-6 $(\mathrm{HCl})$ or $8-10\left(\mathrm{NH}_{4} \mathrm{OH}\right)$ before transferring into a $50 \mathrm{ml}$ Teflon-lined autoclave. The temperature of the reaction was fixed at $200{ }^{\circ} \mathrm{C}$ and was kept for $20 \mathrm{~h}$. After the reaction the samples were washed with DI water $(2 \times)$ for $10 \mathrm{~min}$ in a centrifuge $(4200 \mathrm{rpm})$ then dried overnight at $60{ }^{\circ} \mathrm{C}$ in an oven and stored at $25{ }^{\circ} \mathrm{C}$.

\section{Structural characterisation}

The synthesised materials including the P-Bac-FeOxs were characterised by several analytical techniques such as, scanning electron microscopy (Hitachi SU1510, Japan) at an accelerating voltage of $30 \mathrm{kV}$, Fourier transform infrared (FTIR, Nicolet 6700 Thermo Fisher, Australia) spectroscopy scanned from 4000$400 \mathrm{~cm}^{-1}$ in transmission mode, and XRD measurements were

\begin{tabular}{|c|c|c|c|c|c|c|}
\hline Iron oxide & Colour & Crystal shape & Source & $\mathrm{pH}$ & Temperature & Time of reaction \\
\hline Hematite & Red & $\begin{array}{l}\text { Hexagonal } \\
\text { prisms }\end{array}$ & $\begin{array}{l}\text { Acidic: } \mathrm{Fe}(\mathrm{III}) \text { solution with } \\
\mathrm{Fecl}_{3} \text { or } \mathrm{Fe}\left(\mathrm{NO}_{3}\right)_{3} \text { solution base: } \\
\text { amorphous iron(III)hydroxides }^{12}\end{array}$ & $\begin{array}{l}\text { Acidic: } 1-2 \\
\text { base: } 8-10\end{array}$ & $\begin{array}{l}\text { Acidic }>100{ }^{\circ} \mathrm{C} \\
\text { base: } 100-200{ }^{\circ} \mathrm{C}\end{array}$ & $\begin{array}{l}\text { Acidic: several } \\
\text { days base: - }\end{array}$ \\
\hline Goethite & $\begin{array}{l}\text { Brownish } \\
\text { reddish yellow }\end{array}$ & $\begin{array}{l}\text { Needle, } \\
\text { laths }\end{array}$ & $\begin{array}{l}\text { Acidic: Ferrihydrite precursor base: } \\
\text { amorphous iron(III)hydroxides }{ }^{12}\end{array}$ & $\begin{array}{l}\text { Acidic: } 1-2 \\
\text { base: } 10.5-10.8^{7}\end{array}$ & $\begin{array}{l}\text { Acidic: room temp } \\
\text { base: } 70{ }^{\circ} \mathrm{C}\end{array}$ & $\begin{array}{l}\text { Acidic: } 50 \text { days } \\
\text { base: } 60 \mathrm{~h}\end{array}$ \\
\hline Maghemite & Red to brown & Cubes & $\begin{array}{l}\text { Heating synthetic lepidocrocite or } \\
\text { synthetic magnetite }\end{array}$ & - & $250^{\circ} \mathrm{C}$ & $2 \mathrm{~h}$ \\
\hline Magnetic & Black & Cubes & $\begin{array}{l}\text { Mixed solution of } \mathrm{Fe}(\mathrm{III}) \text { and } \\
\mathrm{Fe}(\mathrm{II}) \text { with the ratio of } 2\end{array}$ & Base: 9-10 & $90^{\circ} \mathrm{C}$ & $30-60 \mathrm{~min}$ \\
\hline Lepidocrocite & Reddish yellow & Laths & Slow hydrolysis of an acidic Fe(III) & $\begin{array}{l}\text { Ideal at } 6.7-6.9 \\
\text { or }<7.5-8\end{array}$ & Room temp & $2-3 \mathrm{~h}$ \\
\hline
\end{tabular}

Table 1 The different properties of the five different oxides and hydroxide of iron under hydrothermal conditions $9.13,14$ 
collected in the range of $2 \theta=20-80^{\circ}$ (scan rate of $10^{\circ} \mathrm{C} \mathrm{min}^{-1}$ ). Particle size distribution (PSD) of all the materials was performed on a Malvern Mastersizer 2000 (Ata Scientific Pty Ltd, Australia).

\section{Results and discussion}

\section{Characterisation of Bac-FeOxs}

An SEM image of P-Bac-FeOxs used in this work is presented in Fig. 1a. The image shows that the morphology of the P-BacFeOxs is comprised of broken and clustered nanowires $<10$ $\mu \mathrm{m}$ in size. The inset shows a clearer image of a bundled of nanowires. XRD confirmed the amorphous structure of the BacFeOx nanowires (Bac-FeOxNWs) (Fig. 1b) and removal of salt impurities from the washing process, which is in good agreement with the literature (Fig. S1 $\dagger$ ).

\section{Effect of pH and mechanism}

After the reaction, the colours of the synthesised Bac-FeOxNWs were observed as that was the first indication that a phase transformation had occurred. Fig. 2 distinctly shows the transition in colour from pH 1 to 10 compared to the control (purified Bac-FeOxNWs, yellow colour), which can be classed into 4 groups. Bac-FeOxNWs-pH 1 is slightly pink, Bac-FeOxNWs-pH 2 is orange, Bac-FeOxNWs-pH 3-4 and 7-10 is a deeper red colour, whereas Bac-FeOxNWs-pH 5-6 is light orange.

Fig. 3a displays the XRD spectra of the different crystalline forms of the Bac-FeOxNWs from $\mathrm{pH} 1$ to 10. Among these curves, the sharp and intensity peaks on $\mathrm{pH} 1$ confirm the highly crystalline form of iron oxide. ${ }^{23}$ The peaks that appear at $2 \theta=24.2,33.2,35.7,42.5,49.5,54.1$ and $64.2^{\circ}$ corresponds to the characteristic peaks of $\alpha-\mathrm{Fe}_{2} \mathrm{O}_{3}$ (JSPDS card no. 89-2810, Fig. S2a $\dagger$ ). ${ }^{15,16}$ The sharp intensity peaks also suggests the high purity of the iron oxide production. ${ }^{23}$ The peaks on $\mathrm{pH} 2$ and 3 a)

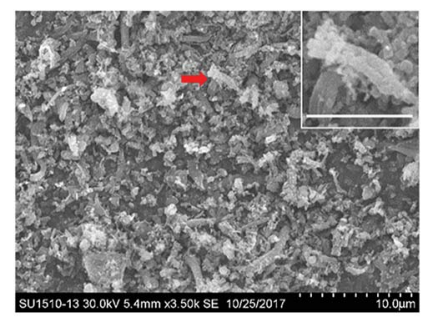

b)

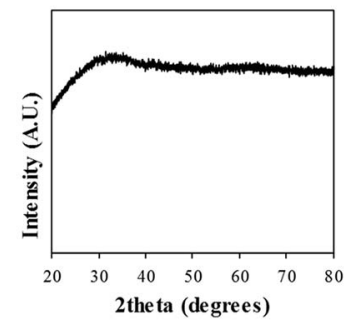

Fig. 1 (a) Low resolution SEM image and (b) XRD spectra of purified Bac-FeOxNWs. Inset is a high-resolution SEM of the twisted nanowires indicated by the red arrow (scale bar $=3 \mu \mathrm{m}$ ).

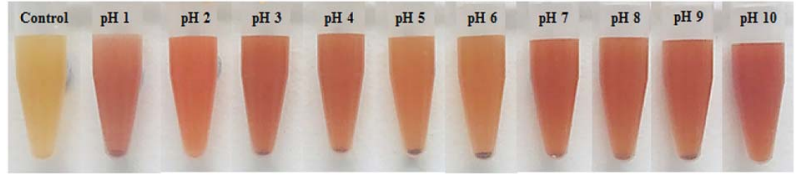

Fig. 2 Photographs of Bac-FeOxNWs before reaction (control) and as a function of $\mathrm{pH}(1-10)$ after the hydrothermal process.
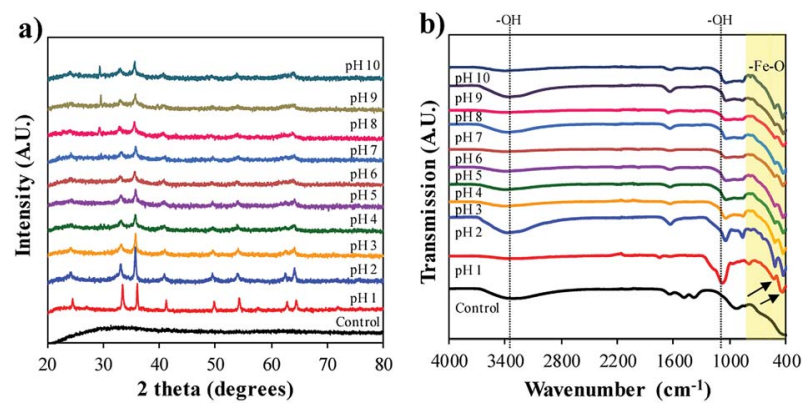

Fig. 3 (a) XRD and (b) FTIR spectra for Bac-FeOxNWs before (control) after the hydrothermal process from $\mathrm{pH} 1$ to 10.

are slightly less intense than $\mathrm{pH} 1$, but still presents the typical peaks. On the other hand, the spectra of $\mathrm{pH} 4$ and $\mathrm{pH} 5$ weakly displays only four of the typical peaks at $2 \theta=33.2,35.7,42.5$ and $54.1^{\circ}$. The less distinct and weak peaks in $\mathrm{pH} 6$ and $7(2 \theta=$ $33.2,35.7^{\circ}$ ) shows that the $\mathrm{pH}$ is not ideal for the complete formation of crystalline iron oxides. At $\mathrm{pH} 8-10$ the XRD peaks are also less well-defined, although there is a phase transition occurring. The successful transformation of the amorphous Bac-FeOxNWs to $\alpha-\mathrm{Fe}_{2} \mathrm{O}_{3}$ is under acidic conditions at $200^{\circ} \mathrm{C}$ for $20 \mathrm{~h}$ is greater than in alkaline conditions at the same temperature and duration. The optimal hydrothermal condition of iron oxides production is $\mathrm{pH} 1$ due to the higher crystalline form obtained.

FTIR spectra shown in Fig. 3b correlates with the findings interpreted from the XRD data. From the purified (control) and synthesised Bac-FeOxNWs curves (pH 1-10), the broad bands at $3400 \mathrm{~cm}^{-1}$ and narrow peaks at $1640 \mathrm{~cm}^{-1}$ correspond to the stretching $-\mathrm{OH}$ groups from the angular deformation of water. ${ }^{17}$ From pH 1-6, two typical bands at $470 \mathrm{~cm}^{-1}$ and $540 \mathrm{~cm}^{-1}$ are observed, which indicate the vibrations of metal and oxide of $\mathrm{Fe}-\mathrm{O}$, which is the form of the hematite phase (Fig. S2b†)..$^{18-20,23}$ However, these two peaks in Bac-FeOxNWs-pH 1, 2 and 3 are much sharper and narrower than those at $\mathrm{pH} 4-10$, confirming the partial and weak transformation of the crystal iron phase. In addition, there is a medium and broad band approx. at $1080 \mathrm{~cm}^{-1}$ in both samples that may be attributed to atmospheric $\mathrm{CO}_{2}$, which commonly occurs in $20 \mathrm{~h}$ hydrothermal treated nano-particles. ${ }^{16,24}$ The hydrothermal process performed at $\mathrm{pH}$ 1-2 provide greater performance for synthesis of crystalline iron oxides.

SEM images of the synthesised Bac-FeOxNWs taken at low and high magnifications further provide evidence for the difference in the nanostructure of each hydrothermal condition. Fig. $4\left(\mathrm{a}-\mathrm{a}^{\prime}\right)$ shows the complete transition from the amorphous structure into high crystalline flower-like structure. These flower-like nanostructures have well-preserved hierarchical patterns of $\alpha$ $\mathrm{Fe}_{2} \mathrm{O}_{3}{ }^{21,22}$ At high SEM magnification, the exterior of each of the nanostructure is composed of irregular sheets. This flower-like nanostructure is attributed to the presence of $\mathrm{HCl}$ in the solution. During the reduction process, iron oxide and $\mathrm{HCl}$ react to form iron chloride $\left(\mathrm{FeCl}_{3}\right)$. The $\mathrm{FeCl}_{3}$ solution is the key factor that contributes to the flower-like formation of $\alpha-\mathrm{Fe}_{2} \mathrm{O}_{3}$ under a heating temperature of $200{ }^{\circ} \mathrm{C} 20-24 \mathrm{~h}^{21}$ Fig. $4\left(\mathrm{~b}-\mathrm{b}^{\prime}\right)$ shows clusters of wrinkled nano-sheets starting to form at $\mathrm{pH} 2$, it is due to the fact that loose and irregular clusters occur under this 


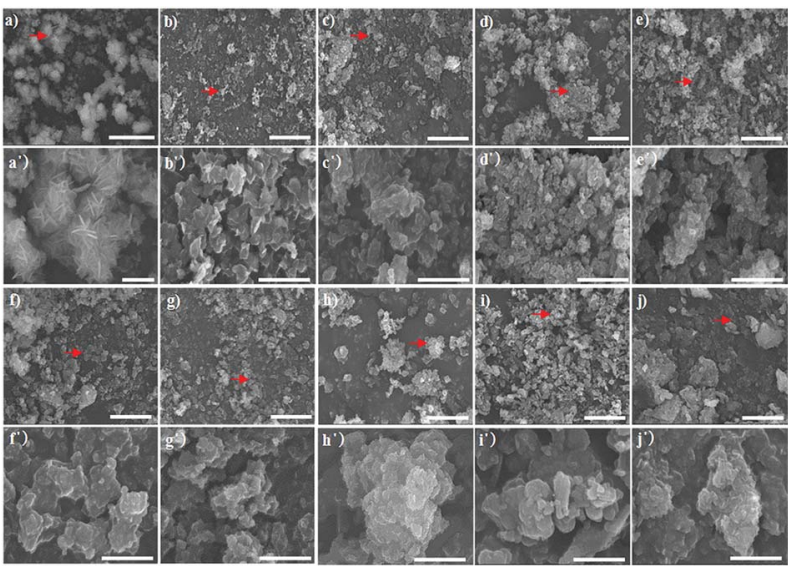

Fig. 4 SEM images of Bac-FeOxNWs performed at $\mathrm{pH} 1-10$ imaged at high $(a-j$, scale bar $=10 \mu \mathrm{m})$ and low $\left(a^{\prime}-j^{\prime}\right.$, scale bar $\left.=2 \mu \mathrm{m}\right)$ resolutions, respectively. The red arrows shown are the areas imaged for the high-resolution SEM.

hydrothermal condition. This structure is maintained at $\mathrm{pH} 3$ (Fig. $4\left(\mathrm{c}-\mathrm{c}^{\prime}\right)$ ) with a similar show of irregular clusters where the breakdown of the structure begins, as observed at $\mathrm{pH} 4-5$ (Fig. $4\left(\mathrm{~d}-\mathrm{d}^{\prime}\right)$ and $\left(\mathrm{e}-\mathrm{e}^{\prime}\right)$ ). From $\mathrm{pH} 6$ to 10 , the structure begins to gather to form irregular and large microparticles, which is the transition from the early stage to the synthesis. ${ }^{25}$ Under highly alkaline conditions from $\mathrm{pH}$ 8-10 these irregular and large clusters become tightly-packed and well-shaped forms, especially in Fig. $4\left(\mathrm{~h}-\mathrm{h}^{\prime}\right){ }^{26}$ Fig. $4(\mathrm{i}$ and $\mathrm{j})$ are the period of transition from the irregular forms into more crystalline structures again. Both $\mathrm{pH} 1$ and $\mathrm{pH} 10$ can provide well crystalline forms of iron oxide, however the acidic condition of $\mathrm{pH} 1$ gives better performance with high crystallization of the flower-like forms.

Particle size distribution of the raw and synthesised materials after the hydrothermal process are present in Fig. 5a. The Bac-FeOxNWs (control) displays a broad PSD ranging from 0.2 to $80.0 \mu \mathrm{m},{ }^{27}$ which is expected due to the presence of many broken nanowires (Fig. 1a). As the nanowires are hydrothermally treated under high temperatures and in an acidic solution their morphology begins to change. The Bac-FeOxNWs synthesised at $\mathrm{pH} 1$ displays a narrow PSD with larger particles $(d(50)=54.5 \mu \mathrm{m})$ compared to the broad PSD (twin peaks) at $\mathrm{pH}$ 2. With increasing $\mathrm{pH}$ from 3 to 4 , the flower-like nanostructures break down into small particles from 13.8 to $10.4 \mu \mathrm{m}$,
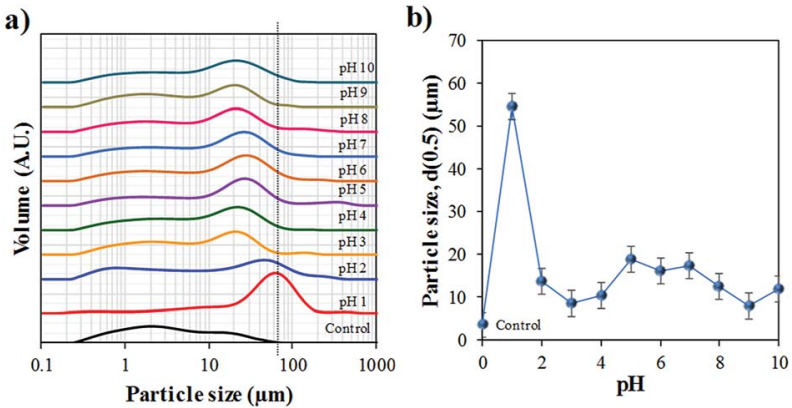

Fig. 5 Particle size distribution (PSD) of the purified (control) and synthesised $\mathrm{Bac}-\mathrm{FeOxNWs}$ from $\mathrm{pH}$ 1-10 after the hydrothermal process. respectively. Around pH 5-7, the particle size of the synthesised Bac-FeOxNWs are consistent $(d(50)=17.2 \mu \mathrm{m})$ as the broken down particles start to form large clusters (Fig. 4(e-g)). Under the hydrothermal treatment in an alkaline condition, the clusters become well-packed and tightly bound from $\mathrm{pH} 8$ to 10 , hence a decrease in the particle size to $12.0 \mu \mathrm{m}$. When the powdered dispersions (Fig. 2) were re-examined after $24 \mathrm{~h}$, it was noticed that all the particles at $\mathrm{pH} 1$ had settled down compared to the well-dispersed stable solutions of all the other pHs. This result further confirms the formation of the larger particles at $\mathrm{pH} 1$ (Fig. 5b) and is complemented by the SEM characterisation.

The study of Mohapatra and Anand ${ }^{9}$ shows that the only reaction product formed is hematite in the $\mathrm{pH}$ range of $0.8-2.6$, however, this is contradictory to the results that claim that the iron product is formed greater under basic $\mathrm{pH} .{ }^{14}$ The difference in results is related to the starting materials used to form $\alpha$ $\mathrm{Fe}_{2} \mathrm{O}_{3}$. Majority of the studies use the iron chemical precursors to form the end product, whereas in this work we start with the natural amorphous iron oxide instead. Considering the XRD, FTIR, SEM and PSD results, the optimal hydrothermal treatment is under acidic conditions for Bac-FeOxNWs at a reaction temperature of $200{ }^{\circ} \mathrm{C}$ with $\mathrm{pH} 1$ and a reaction time of $20 \mathrm{~h}$ for the complete transformation of $\alpha-\mathrm{Fe}_{2} \mathrm{O}_{3}$. The reaction is successfully reduced due to the pink coloured powder that is obtained as illustrated in Fig. 2 than the majority of orange powders achieved for the other $\mathrm{pH}$ values. Although, red powders were obtained under alkaline pHs their crystalline structures are weak and are not fully developed.

This 'nucleation, growth and ostwald ripening' behaviour is common for the synthesis of iron oxides under different conditions (e.g. time, temperature, environment). ${ }^{28-32}$ Under hydrothermal conditions, starting at neutral $\mathrm{pH} 7$, by decreasing $\mathrm{pH}$ (acidic) the system shows that the particles grew through Ostwald ripening, while at basic $\mathrm{pH}$ the particles underwent continuous nucleation and growth to form aggregates, ${ }^{23,25}$ which confirms the SEM and PSD data.

\section{Applications}

The potential use of $\alpha-\mathrm{Fe}_{2} \mathrm{O}_{3}$ produced at the optimal acidic condition ( $\mathrm{pH} 1$ ) from the hydrothermal reduction process was tested with 2 different applications. Photodegradation of Rhodamine B (RhB, Sigma Aldrich, Australia) was performed on the synthesized product. Details of the experimental set up is described elsewhere. ${ }^{4}$ The data shows that after $15 \mathrm{~min}$ of exposure to visible light the amount of $\mathrm{RhB}$ in the solution had decreased as measured with UV-vis spectroscopy (Shimadzu UVVis 1601, Japan) (Fig. 6a). This suggests that both the aromatic rings and chromophores of $\mathrm{RhB}$ have been destroyed, therefore demonstrating that the synthesized $\alpha-\mathrm{Fe}_{2} \mathrm{O}_{3}$ material has photocatalytic properties. The product was also used as an adsorbent for the removal of heavy metal ions (e.g. arsenic) as illustrated in Fig. 6b. The adsorption study was carried out at room temperature $\left(22^{\circ} \mathrm{C}\right)$ with an initial concentration of $10 \mathrm{mg}$ $\mathrm{ml}^{-1}$ using $10 \mathrm{mg}$ of adsorbent. The experimental procedure is given elsewhere. ${ }^{5}$ Comparative studies with our previous work ${ }^{4}$ 

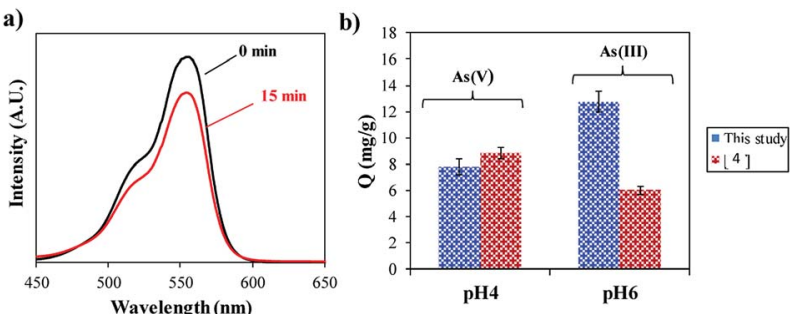

Fig. 6 (a) UV-Vis spectra of the degradation of RhB at $15 \mathrm{~min}$, and (b) and adsorption capacity (Q) of $A s(I I)$ and $A s(v)$ ions after 90 min.

shows similar adsorption capacity $(Q)$ for $\operatorname{As}(\mathrm{v})\left(\sim 9 \mathrm{mg} \mathrm{g}^{-1}\right)$ but a double improvement in the adsorption of As(III) $\left(13 \mathrm{mg} \mathrm{g}^{-1}\right)$ performed at $\mathrm{pH} 4$ and 6 , respectively, after $90 \mathrm{~min}$. This could be related to the greater surface area of the crystalline nanoflowers compared to the untreated Bac-FeOxNWs, which was smaller in particle size.

\section{Conclusions}

In this work, we demonstrated for the first time the hydrothermal reduction of iron oxides from bacteria biofilm waste under acidic and basic conditions at a fixed reaction temperature and time. Comparing the results that were achieved at basic $\mathrm{pH}$, the evidence strongly shows that the optimal condition for the transformation of amorphous iron oxide nanowires to crystalline $\alpha-\mathrm{Fe}_{2} \mathrm{O}_{3}$ is under acidic condition where the $\mathrm{pH}$ is 1. Highly crystalline nano-flower structures were obtained with a large particle size of $54.5 \mu \mathrm{m}$. We also showed that the nanoflower $\alpha-\mathrm{Fe}_{2} \mathrm{O}_{3}$ structures have photocatalytic activity and adsorbent properties for heavy metal ions. This one-pot synthesis reaction makes this a simple waste-free method which requires low cost to produce, thereby providing excellent opportunity to recycle this abundant waste material for environmental and catalysis applications.

\section{Conflicts of interest}

There are no conflicts to declare.

\section{Acknowledgements}

The authors acknowledge the financial support of the Australian Research Council (IH 150100003) Graphene Enabled Industry Transformation Hub and The University of Adelaide.

\section{References}

1 G. Viau, R. Brayner, L. Poul, N. Chakroune, E. Lacaze, F. Fiévet Vincent and F. Fiévet, Chem. Mater., 2003, 15, 486. 2 F. Gao and Q. Lu, J. Mater. Sci., 2007, 43, 2377.

3 T. Kumeria, S. Maher, Y. Wang, G. Kaur, L. Wang, M. Erkelens, P. Forward, M. F. Lambert, A. Evdokiou and D. Losic, Biomacromolecules, 2016, 17, 2726.

4 L. Wang, T. Kumeria, A. Santos, P. Forward, M. F. Lambert and D. Losic, ACS Appl. Mater. Interfaces, 2016, 8, 2011020119.
5 I. Andjelkovic, S. Azari, M. Erkelens, P. Forward, M. F. Lambert and D. Losic, RSC Adv., 2017, 7, 3941.

6 L. Shen, Y. Qiao, Y. Guo and J. Tan, Ceram. Int., 2013, 39, 737.

7 L. Gao, Y. Liu, D. Kim, Y. Li, G. Hwang, P. C. Naha, D. P. Cormode and H. Koo, Biomaterials, 2016, 101, 272.

8 Y. Liu, P. C. Naha, G. Hwang, D. Kim, Y. Huang, A. SimonSoro, H. Jung, Z. Ren, Y. Li, S. Gubara, F. Alawi, D. Zero, A. T. Hara, D. P. Cormode and H. Koo, Nat. Commun., 2018, 9, 2920.

9 M. Mohapatra and S. Anand, Int. J. Eng. Sci. Technol., 2010, 2, 127.

10 A. Matthews, Am. Mineral., 1976, 61, 927.

11 J. D. Bernal, D. R. Dasgupta and A. L. Mackay, Clay Miner. Bull., 1958, 5, 15.

12 N. V. Sidgwick, The Chemical Elements and Their Compounds, vol. II, Oxford University Press, 1950.

$13 \mathrm{U}$. Schwertman and R. M. Cornell, Iron oxides in the Laboratory, Wiley-Vch, 2000.

14 M. Y. Nassar, I. S. Ahmed, T. Y. Mohamed and M. Khatab, RSC Adv., 2016, 6, 2000.

15 A. N. Christensen, Acta Chem. Scand., 1968, 22, 1487.

16 R. Karunagaran, C. Coghlan, T. T. Tung, S. Kabiri, D. N. H. Tran, C. J. Doonan and D. Losic, New J. Chem., 2017, 41, 15180.

17 C. Yan, J. Nishida, R. Yuan and M. D. Fayer, J. Am. Chem. Soc., 2016, 138, 9694.

18 H. Namduri and S. Nasrazadani, Corros. Sci., 2008, 50, 2493.

19 A. M. Jubb and H. C. Allen, ACS Appl. Mater. Interfaces, 2010, 2, 2804.

20 R. Riasat and G. Nie, J. Nanomater., 2016, 7, 3.

21 K. Xie, X. Wang, Z. Liu, A. Alsaedi, T. Hayat and X. Wang, Applied Physics for Engineering, 2014, 15, 673.

22 W. Zhang, J. Chen, X. Wang, H. Qi and K. Peng, Appl. Organomet. Chem., 2009, 23, 200.

23 M. Sinha, S. Sahu, P. Meshram, L. Prasad and B. Pandey, Powder Technol., 2015, 276, 217.

$24 \mathrm{R}$. Cornell and U. Schwertmann, Iron oxides, $2^{\text {nd }}$ edn, WileyVCH, Weinheim, 2003.

25 K. Jensen, H. Andersen, C. Tyrsted, E. Bojesen, A. Dippel, N. Lock, S. Billinge, B. Iversen and M. Christensen, ACS Nano, 2014, 8, 10708.

26 J. Park, K. Hwang, G. Park, J. Noh, H. Park, Y. Kim and H. Hyeron, Nat. Mater., 2004, 3, 891.

27 O. Horner, S. Neveu, S. de Montredon, M. Siaugue and V. Cabuil, J. Nanopart. Res., 2009, 48, 4788.

28 N. T. K. Thanh, N. Maclean and S. Mahiddine, Chem. Rev., 2014, 114, 7610.

29 Y. Hu, C. Neil, B. Lee and Y.-S. Jun, Environ. Sci. Technol., 2013, 47, 9198.

30 Y. Hu, C. Neil, B. Lee and Y.-S. Jun, Environ. Sci. Technol., 2013, 48, 299.

31 Y.-S. Jun, D. Kim and C. W. Neil, Acc. Chem. Res., 2016, 49, 1681.

32 H. S. Dehsari, M. Heidari, A. H. Ribeiro, G. Jakob, D. Donadio, R. Potestio and K. Asadi, Chem. Mater., 2017, 29, 9648. 